\title{
Hyperthermia for Breast Cancer Treatment Using Slotted Circular Patch Antenna
}

\author{
Mussa Elsaadi, Yousef Aid, Mustafa Abbas, Amani Embarek, Khaleel Salih \\ Electronic and Electrical Engineering, Tobruk University, Tobruk, Libya \\ Email: elsaadi.mussa@gmail.com
}

How to cite this paper: Elsaadi, M., Aid, Y., Abbas, M., Embarek, A. and Salih, K. (2019) Hyperthermia for Breast Cancer Treatment Using Slotted Circular Patch Antenna. Circuits and Systems, 10, 37-44. https://doi.org/10.4236/cs.2019.103003

Received: February 17, 2019

Accepted: March 26, 2019

Published: March 29, 2019

Copyright (อ 2019 by author(s) and Scientific Research Publishing Inc. This work is licensed under the Creative Commons Attribution International License (CC BY 4.0).

http://creativecommons.org/licenses/by/4.0/

\begin{abstract}
The primary intent of this paper is to investigate the potential of using a slotted circular patch antenna at $2.45 \mathrm{GHz}$ for breast tumor hyperthermia treatment. A cancer treatment model consisting of a microstrip patch antenna and breast phantom comprising tumor is designed and simulated in CST Studio Suite 2018. The radiation properties of the proposed antenna attain $3 \mathrm{~dB}$ beam width of $74.1^{\circ}$ and $70.5^{\circ}$ for the E-Plane and the H-plane, respectively. The breast phantom is exposed to the designed antenna radiation for $10 \mathrm{mi}-$ nutes, leading to raise the breast phantom temperature by $8.5^{\circ} \mathrm{C}$ and $11.4^{\circ} \mathrm{C}$ once the antenna pumped power is 1.5 and 2 watt, respectively. By considering 10 minutes as an exposure time, the breast temperature as a function of the applied antenna power is studied and compared with previous published results.
\end{abstract}

\section{Keywords}

Hyperthermia Treatment, Breast Cancer, Microstrip Antenna Design

\section{Introduction}

Hyperthermia is extremely exploited to acquire a therapeutic level of the tumor through increasing its temperature at which the malignant tissues are heat-dependent or destroyed as a result of the increased local temperature above $42^{\circ} \mathrm{C}$ [1]. The heating is an effective technique to enhance the blood flow rate inside the tumors as the oxygenation is inherently low [2]. The hyperthermia has been considered the effective cancer therapy compared to the chemotherapy (i.e., chemical toxins) and the X-ray (i.e., ionizing radiation) [3]. In principal, thermal conduction, ultrasound and electromagnetic (EM) are different heating techniques which have been explored for hyperthermia treatment purposes [4]. Among these techniques, EM applicators play a significant role in medical 
treatments, mainly within the breast cancer treatment process [5]. The EM applicators are divided into two different types, external and interstitial applicators. The external applicators are placed on the body surface where the tumors are located nearby while the interstitial ones are inserted inside the body at the tumor position.

In general, hyperthermia treatment comes in three different categories depending on the tumor position, namely whole body hyperthermia, regional hyperthermia and local hyperthermia [6]. The microwave hyperthermia treatment, as a promising approach, for breast tumor is presented in recently published studies [7] [8]. Antennas with different shapes were employed for temperature increase purposes [9] [10] [11]. However, the feed method and the shape of this antenna are more complex.

In the current work, the proposed antenna originated with a slotted circular patch shape. The antenna is designed and simulated, alongside breast phantom involving tumor using EM thermal co-simulation technique. The current antenna maintains a decent performance in terms of the exposure time, temperature evaluation and the input power when compared to the aforementioned antennas. The ultimate goal of the work is to realize efficient and high gain slotted circular antenna array for hyperthermia breast tumor therapy system, while the investigation here is to study the design of a single slotted circular antenna (a scaled version) in the first instance.

\section{Patch Antenna Design}

This section purpose is to design a slotted circular patch antenna at the industrial, scientific and medical (ISM) radio band. The ISM band denotes a group of the radio spectrum, the most exploited frequencies are $0.434 \mathrm{GHz}$ and $2.45 \mathrm{GHz}$. To design a microstrip patch antenna, three key factors should be carefully specified. These elements are the frequency of operation, the height of substrate and the dielectric constant of substrate. In this paper, the functioning frequency is selected to be $2.45 \mathrm{GHz}$ fitting a wide range of medical applications such as the breast cancer detection and treatment. For medical application purposes, it is important that the employed antenna is not massive. Therefore, the selected height is $1.57 \mathrm{~mm}$ and the dielectric material of the substrate is Duroid 5880 with 2.2 dielectric constant.

The final layout of the centered slotted circular antenna is shown in Figure 1. The optimum dimension of the circular patch and the centered slot are $22.9 \mathrm{~mm}$ and $1 \mathrm{~mm}$, respectively. The length of the feed line is $24 \mathrm{~mm}$ while its width is $0.7 \mathrm{~mm}$. The match line has a length and width of $15 \mathrm{~mm}$ and $4.8 \mathrm{~mm}$, respectively. The selected substrate is square in dimension with $100 \mathrm{~mm}^{2}$ as similar to the metallic ground plane. To match the applied power, the height and the width of wave port are carefully selected. To ensure the radiation cannot be reflected back, the air box length is adjustable.

The return loss performance (S11) is shown in Figure 2. The S11 is the main 


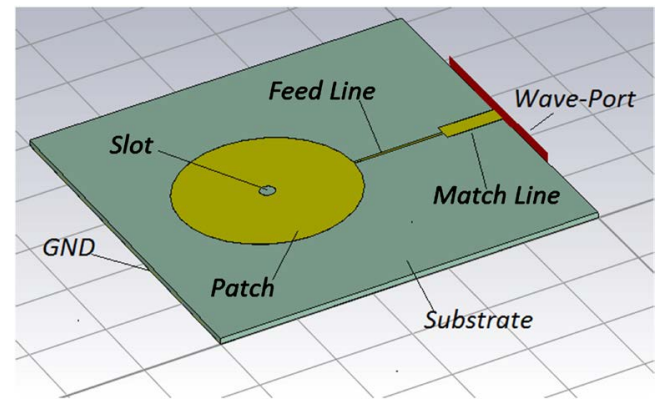

Figure 1. The structure of the slotted circular antenna.

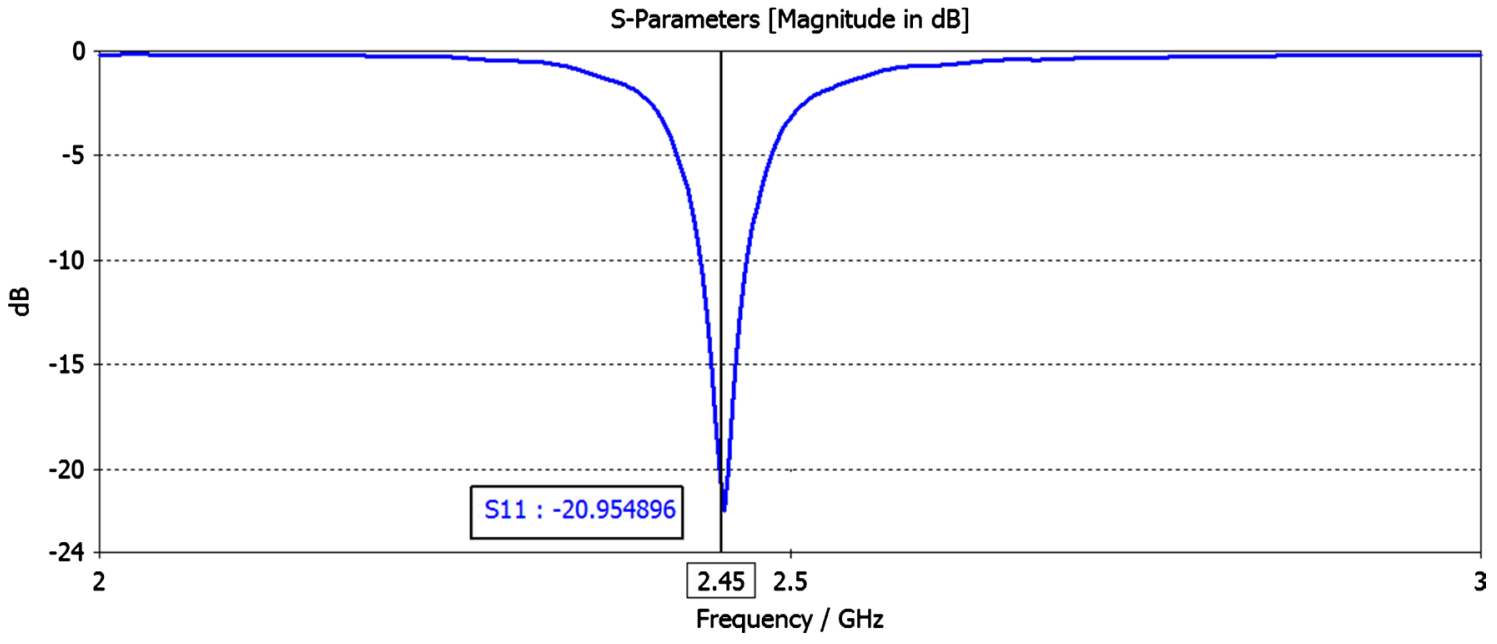

Figure 2. The return loss performance.

parameter to inspect the power reflection of the antenna. It can be seen from Figure 2 that the return loss shows a decent performance at the operating frequency $(2.45 \mathrm{GHz})$ with better than $-20 \mathrm{~dB}$. This indicates that the incident power is efficiently transferred to the metallic circular patch, in turn, to the breast phantom afterward. It is also obvious that the bandwidth at the operating frequency is around $32 \mathrm{MHz}$.

The radiation patterns in the E-plane and $\mathrm{H}$-plane of the $2.45 \mathrm{GHz}$ antenna are shown in Figure 3 and Figure 4. These planes are also known as the Azimuth plane and Elevation plane, respectively. It can be seen that the antenna has a $3 \mathrm{~dB}$ beam width with $74.1^{\circ}$ at the azimuth plane whereas $70.5^{\circ}$ at the elevation plane. It is noticeable from these radiation patterns that the Gain is above $7.5 \mathrm{~dB}$ presenting individually in a $3 \mathrm{D}$ pattern in Figure 5.

\section{Breast Cancer Hyperthermia Treatment}

The current section presents the main goal of this work. The proposed model for the breast cancer treatment, using the radiation properties of the designed antenna in the previous section, is introduced. In principle, the proposed circular antenna emits Radio Frequency (RF) signals, as non-ionizing heating source, towards the modelled breast phantom where the breast tissues receive and absorb the incident antenna power. The highest value of the applied power is con- 
trolled and individual focused at the tumor position, preserving the healthy tissues absorbed power-free.

There is a linear relationship between the emitted RF signals and the encouraged temperature distribution inside the breast phantom. Subsequently, this induced temperature can be exploited in breast cancer hyperthermia therapy. A simple cone is used to create the $3 \mathrm{D}$ breast phantom at which the lower radius is $0 \mathrm{~mm}$ and the upper radius is $200 \mathrm{~mm}$, while the height is $130 \mathrm{~mm}$. The breast

Farfield Gain Abs (Phi=0)

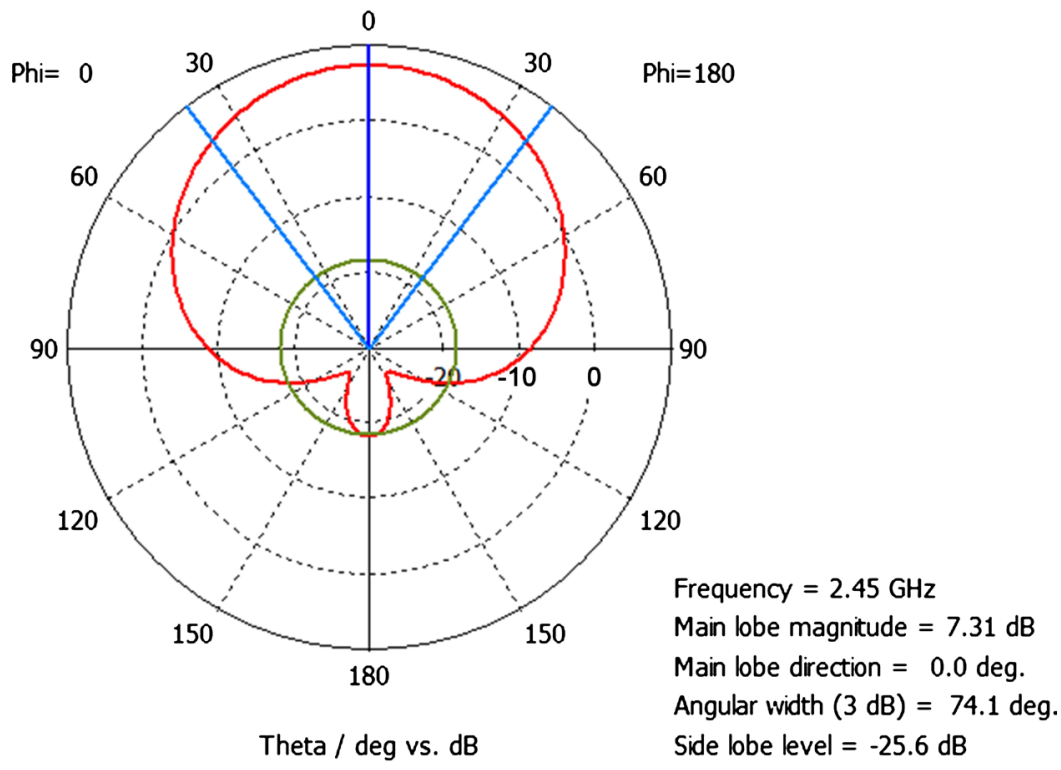

Figure 3. Radiation pattern in E-Plane/Azimuth plane.

Farfield Gain Abs (Phi=90)

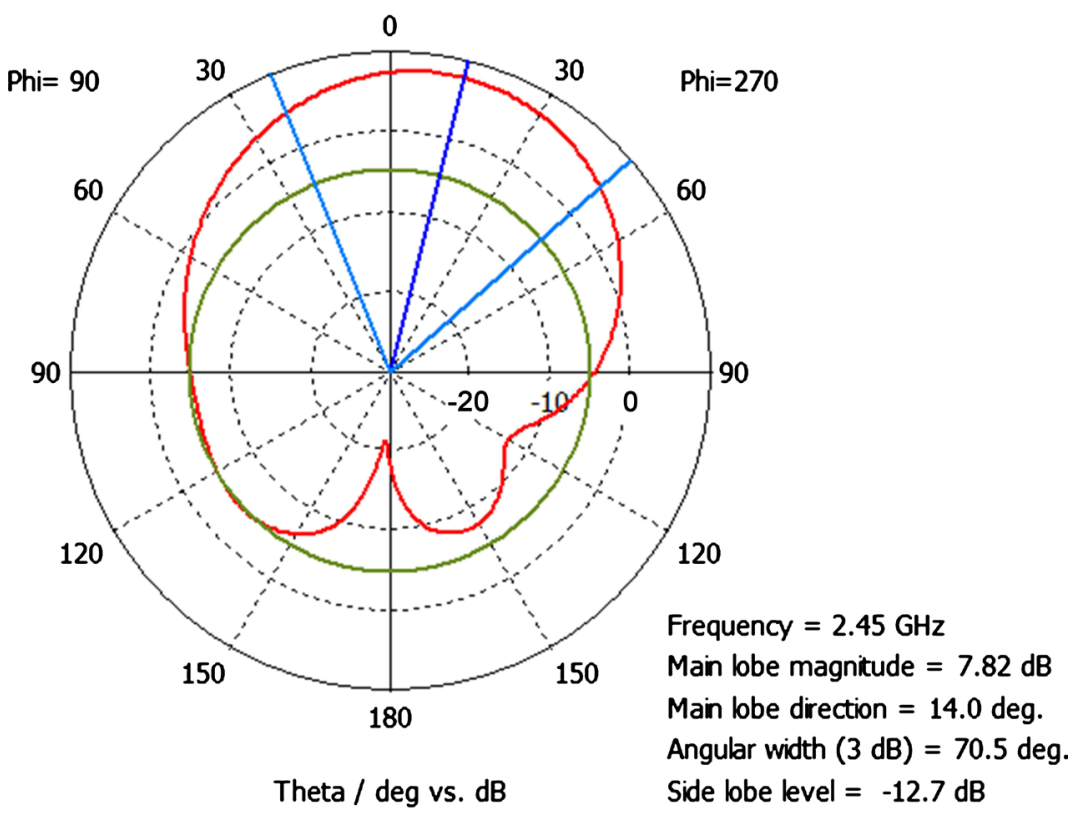

Figure 4. Radiation pattern in H-Plane/ Elevation plane. 
phantom is placed $70 \mathrm{~mm}$ distant from the designed microstrip antenna. Likewise, a sphere with $20 \mathrm{~mm}$ diameter representing the inserted tumor inside the breast phantom is designed. Figure 6 shows the structure, which is simulated and its prospective results are discussed in the following section.

\section{Results and Discussion}

The electrical and thermal properties of materials used to create the breast phantom and the tumor are illustrated in Table 1. The breast consists of a set of tissues, but for investigation purpose, the breast tissues are averaged as a single tissue at $2.45 \mathrm{GHz}$.

By considering $37^{\circ} \mathrm{C}$ of the normal body temperature, the induced energy of the antenna is applied to the breast phantom over a 10 minutes' exposure time and with input power of $0.5 \mathrm{~W}$. Figure 7 shows a maximum temperature of

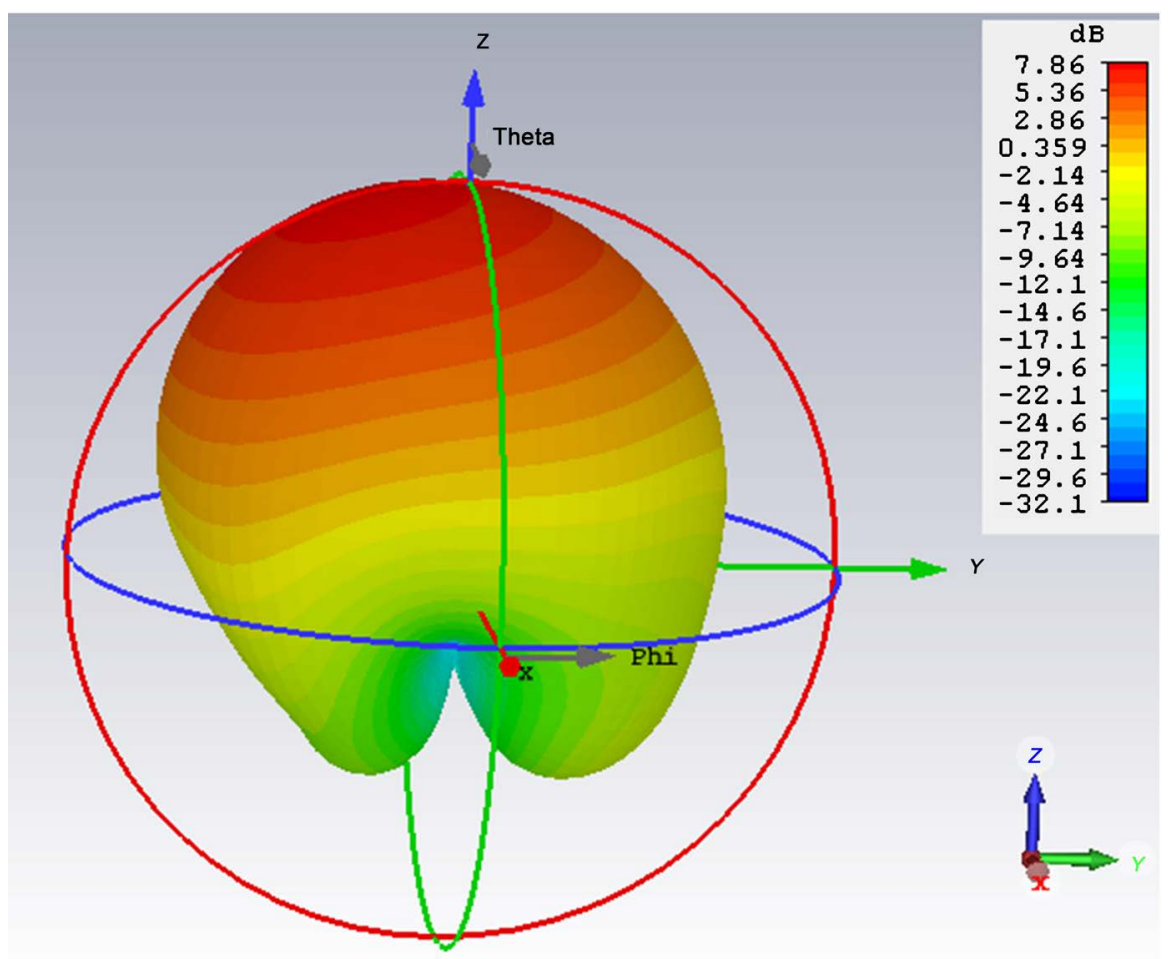

Figure 5. 3D-Gain radiation pattern.

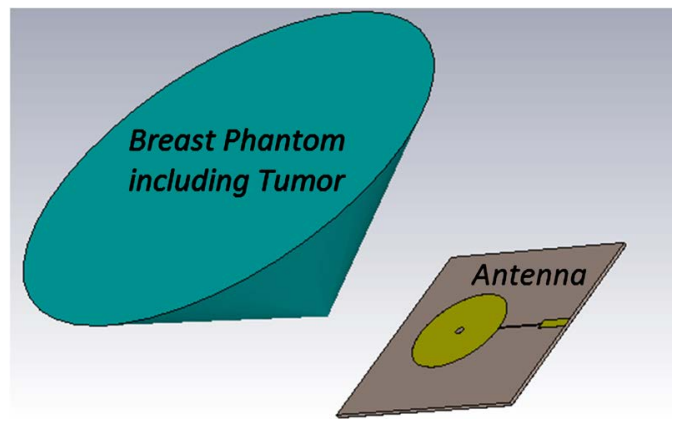

Figure 6. The proposed model configuration. 
$39.8^{\circ} \mathrm{C}$, which is insufficient for hyperthermia treatment.

In order to obtain the required temperature (i.e., above $42^{\circ} \mathrm{C}$ ), the antenna input power should be scaled as shown in Figures 8-10. It is clear that there is a linear proportional relationship between the applied power and the temperature inside the breast phantom. As a result, the input power of $1.5 \mathrm{~W}$ or $2 \mathrm{~W}$ provide an increasing in terms of the temperature to be above $8^{\circ} \mathrm{C}$ and $11^{\circ} \mathrm{C}$ in respective, which are appropriate for hyperthermia treatment when the exposure time is set to 10 minutes. Table 2 demonstrates a comparison of the current results with respect to previous published results, at which the current results are compromise in terms of the exposure time and the input power of the antenna.

Table 1. The average electrical and thermal properties of the breast at $2.45 \mathrm{GHz}$.

\begin{tabular}{lccccc}
\hline $\begin{array}{c}\text { Tissue } \\
\text { name }\end{array}$ & $\begin{array}{c}\text { Permittivity } \\
(\mathrm{F} / \mathrm{m})\end{array}$ & $\begin{array}{c}\text { Electrical } \\
\text { Conductivity }(\mathrm{S} / \mathrm{m})\end{array}$ & $\begin{array}{c}\text { Density } \\
\left(\mathrm{Kg} / \mathrm{m}^{3}\right)\end{array}$ & $\begin{array}{c}\text { Heat Capacity } \\
(\mathrm{KJ} / \mathrm{K} / \mathrm{kg})\end{array}$ & $\begin{array}{c}\text { Thermal Conductivity } \\
(\mathrm{W} / \mathrm{K} / \mathrm{m})\end{array}$ \\
\hline Tumor & 50 & 2.1 & 1041 & 3.5 & 0.5 \\
Breast & 9 & 0.4 & 1058 & 3.639 & 0.42 \\
\hline
\end{tabular}

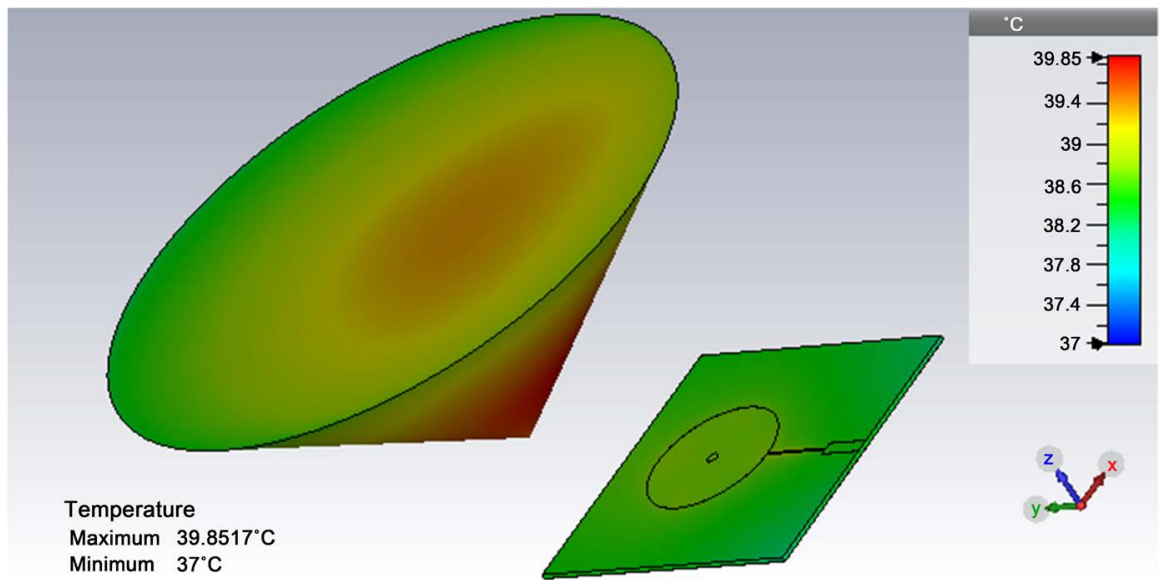

Figure 7. The heat distribution at $0.5 \mathrm{~W}$.

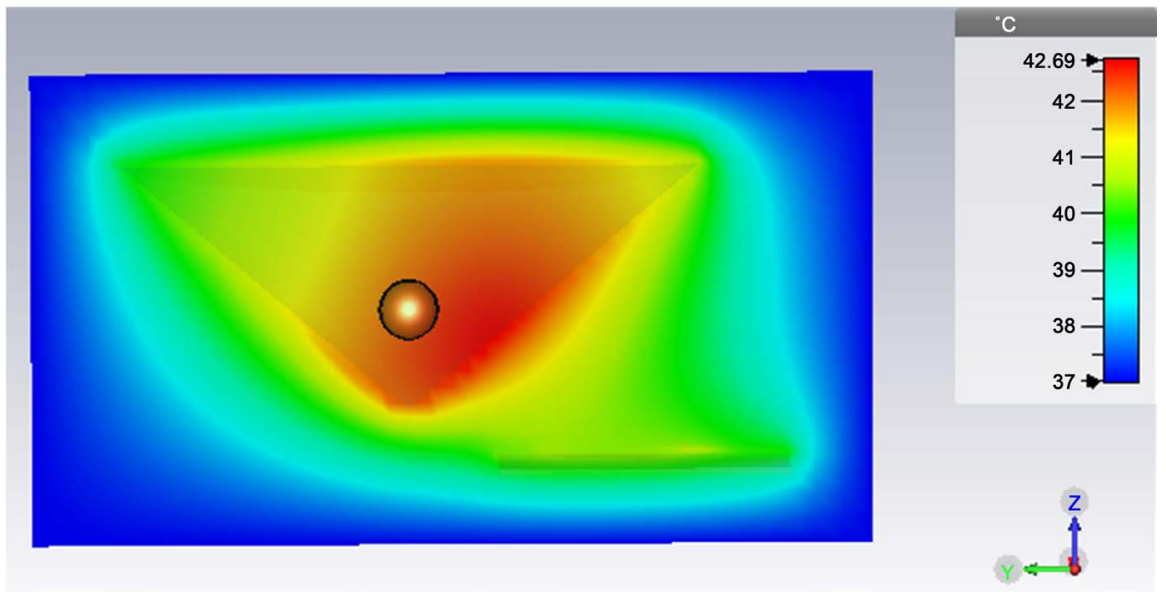

Figure 8. The heat distribution at $1 \mathrm{~W}$. 


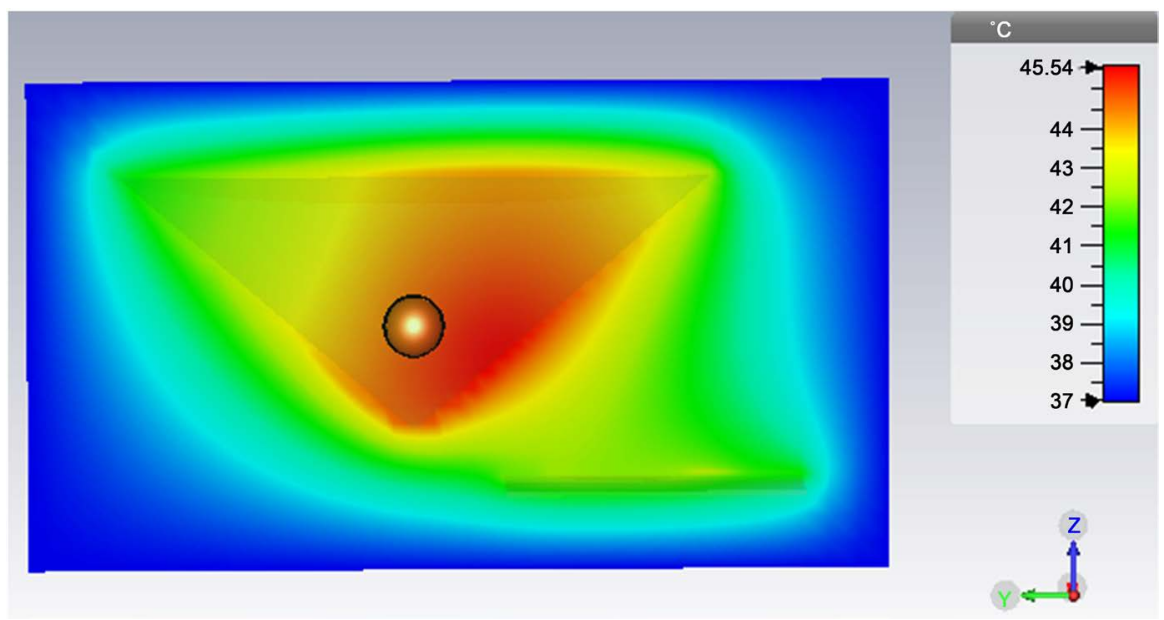

Figure 9. The heat distribution at $1.5 \mathrm{~W}$.

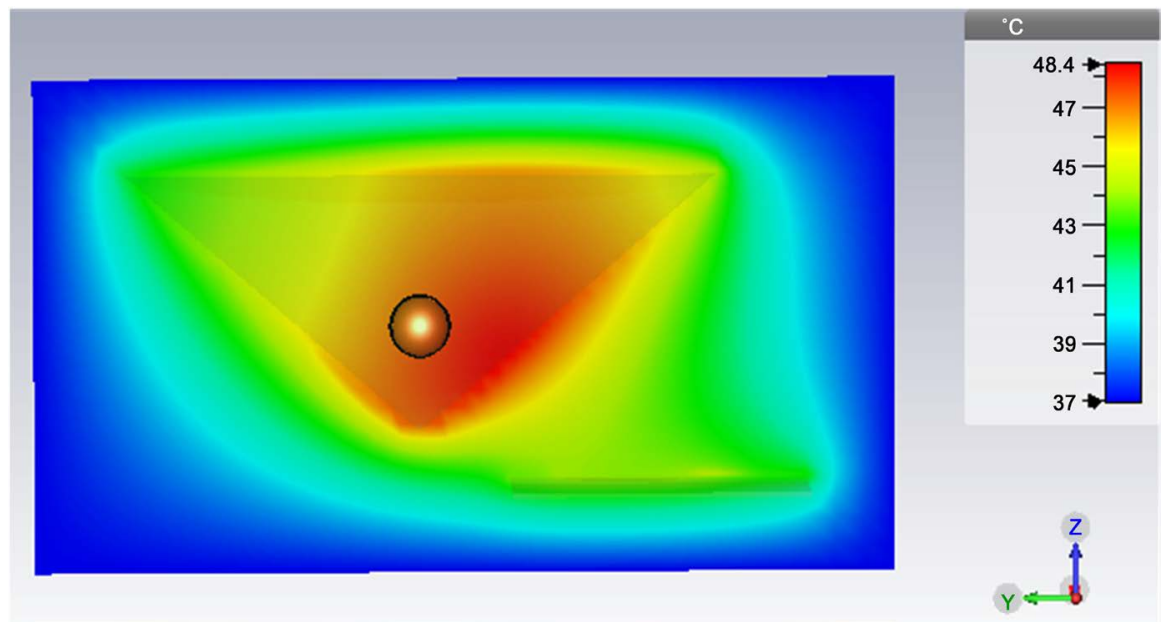

Figure 10. The heat distribution at $2 \mathrm{~W}$.

Table 2. A comparison with other published results.

\begin{tabular}{ccccc}
\hline $\begin{array}{c}\text { Applied Power } \\
\text { (Watt) }\end{array}$ & $\begin{array}{c}\text { Exposure time } \\
\text { (Minutes) }\end{array}$ & $\begin{array}{r}\text { Operating } \\
\text { Frequency }(\mathrm{GHz})\end{array}$ & $\begin{array}{c}\text { Increased Temperature } \\
\left({ }^{\circ} \mathrm{C}\right)\end{array}$ & Reference \\
\hline 1 & 8.65 & 1.6 & 3 & {$[9]$} \\
45 & 30 & 4.2 & 6 & {$[10]$} \\
50 & 3 & 0.434 & 12 & {$[11]$} \\
1.5 & 10 & 2.45 & 8.5 & Current Paper \\
2 & 10 & 2.45 & 11.4 & Current Paper \\
\hline
\end{tabular}

\section{Conclusion}

The potential of using a slotted circular patch antenna at $2.45 \mathrm{GHz}$ for breast tumor hyperthermia treatment was investigated in this paper. The steps to fabricate and measure the proposed antenna to validate the current simulated results are taken into consideration through the next phase, where the ultimate goal to realize efficient and high gain slotted circular antenna array. 


\section{Conflicts of Interest}

The authors declare no conflicts of interest regarding the publication of this paper.

\section{References}

[1] Dewey, W.C. (2009) Arrhenius Relationships from the Molecule and Cell to the Clinic. International Journal of Hyperthermia, 25, 3-20. https://doi.org/10.1080/02656730902747919

[2] Song, C.W.M., Shakil, A., Griffth, R.J. and Okajima, K. (1997) Improvement of Tumor Oxygenation Status by Mild Temperature Hyperthermia Alone or in Combination Carbonage. Semin Oncol, 24, 626632.

[3] Roemer, R.B. (1999) Engineering Aspects of Hyperthermia Therapy. Annual Review of Biomedical Engineering, 1, 347-376. https://doi.org/10.1146/annurev.bioeng.1.1.347

[4] Vorst, A.V., Rosen, A. and Kotsuka, Y. (2006) RF/Microwave Interaction with Biological Tissues. Vol. 1, John Wiley \& Sons, Hoboken, NJ, 1-330. https://doi.org/10.1002/0471752053.ch

[5] Guo, B., Xu, L. and Li, J. (2005) Time Reversal Based Microwave Hyperthermia Treatment of Breast Cancer. The 39th Asilomar Conference on Signals, Systems and Computers, Pacific Grove, CA, 30 October-2 November 2005, 290-293.

[6] Bull, J.M., Scott, G.L., Strebel, F.R., et al. (2008) Fever-Range Whole-Body Thermal Therapy Combined with Cisplatin, Gemcitabine, and Daily Interferon-Alpha. International Journal of Hyperthermia, 24, 649-662. https://doi.org/10.1080/02656730802104740

[7] Zastrow, E., Hagness, S.C. and Van Veen, B.D. (2010) 3D Computational Study of Non-Invasive Patient-Specific Microwave Hyperthermia Treatment of Breast Cancer. Physics in Medicine and Biology, 55, 3611. https://doi.org/10.1088/0031-9155/55/13/003

[8] Trefna, H.D., Vrba, J. and Persson, M. (2010) Time-Reversal Focusing in Microwave Hyperthermia for Deep-Seated Tumors. Physics in Medicine and Biology, 55, 2167. https://doi.org/10.1088/0031-9155/55/8/004

[9] Asili, M., Chen, P., Hood, A.Z., Purser, A., Hulsey, R., Johnson, L. and Topsakal, E. (2015) Flexible Microwave Antenna Applicator for Chemo-Thermotherapy of the Breast. IEEE Antennas and Wireless Propagation Letters, 14, 1778-1781. https://doi.org/10.1109/LAWP.2015.2423655

[10] Nguyen, P.T., Abbosh, A. and Crozier, S. (2016) Three-Dimensional Microwave Hyperthermia for Breast Cancer Treatment in a Realistic Environment Using Particle Swarm Optimization. IEEE Transactions on Biomedical Engineering, 64, 1335-1344. https://doi.org/10.1109/TBME.2016.2602233

[11] Fiser, O., Merunka, I. and Vrba, J. (2015) Design, Evaluation and Validation of Planar Antenna Array for Breast Hyperthermia Treatment. 2015 Conference on Microwave Techniques (COMITE), Pardubice, 22-23 April 2015, 1-4. https://doi.org/10.1109/COMITE.2015.7120228 